\title{
Molecular screening for familial hypercholesterolaemia: consequences for life and disability insurance
}

Sietske JM Homsma, Roeland Huijgen, Saskia Middeldorp, Eric JG Sijbrands and John JP Kastelein

European Journal of Human Genetics (2008) 16, 275; doi:10.1038/sj.ejhg.5201972

Correction to: European Journal of Human Genetics (2007) doi:10.1038/sj.ejhg.5201940; published online 24 October 2007
Following the above online publication, the authors have noticed an error in the name of the second author in reference 21, van WS should be van Wissen $\mathrm{S}$. 